\title{
Functional Synaptic Circuits in the Subplate During Fetal and Early Postnatal Development of Cat Visual Cortex
}

\author{
Eckhard Friauf, ${ }^{\mathrm{a}}$ Susan K. McConnell, ${ }^{\mathrm{b}}$ and Carla J. Shatz \\ Department of Neurobiology, Stanford University School of Medicine, Stanford, California 94305
}

\begin{abstract}
Among the first postmitotic cells of the cerebral cortex is a special population located below the cortical plate: the subplate neurons. These neurons reach a high degree of morphological maturity during fetal life, well before the neurons of the cortical layers have matured, yet nearly all of these cells die after birth in the cat. Subplate neurons are also known to receive synaptic contacts. Here we have investigated whether these contacts are functional by making intracellular recordings from subplate neurons in cortical slices maintained in vitro. Subplate neurons were identified based on their location and morphology by injecting them with biocytin following the intracellular recordings.
\end{abstract}

At all ages studied between embryonic day $\mathbf{5 0}$ and postnatal day 9, electrical stimulation of the optic radiations elicited EPSPs and synaptlc and antidromic spikes in subplate neurons, indicating that some of the synapses seen at the ultrastructural level are indeed capable of synaptic transmission. The spiking patterns of 39 morphologically identified subplate neurons were examined by injecting depolarizing current, which revealed that a large majority gave only a single spike or a brief train of spikes in response to maintained depolarization, in contrast to the regular spiking pattern found in many neurons of adult cortex. Biocytin injections into subplate neurons revealed that they are a morphologically heterogeneous population with respect to their dendritic branching patterns; roughly half were inverted pyramids, the classic subplate neuron morphology. The axonal processes of subplate neurons were remarkable in that many not only arborized within the subplate, but also entered the cortical plate and terminated in the marginal zone. At early postnatal ages, these axons also gave off collaterals within cortical layer 4.

The results of this study indicate that subplate neurons participate in synaptic microcircuits during development. While the presynaptic identity of the input to subplate neurons is not known conclusively, it is likely that geniculocortical axons, which wait in close proximity to subplate

Received Jan. 8, 1990; revised March 15, 1990; accepted March 22, 1990.

This work was supported by NIH grant EY02858 to C.J.S., NRSA EY06028 to S.K.M., and a NATO/DAAD postdoctoral fellowship to E.F. We wish to thank Richard Mooney for his advice on using the biocytin injection technique and for his helpful comments on the manuscript; Doug Coulter, Larry Katz, Robert Malenka, and Heiko Luhmann for help with preparation of slices; and Antonella Antonini, Anirvan Ghosh, and Mark Siegel for assistance with the fetal surgeries.

Correspondence should be addressed to Dr. Carla J. Shatz at the above address.

a Present address: Department of Animal Physiology, Biology III, Universität Tübingen, Morgenstelle 28, D-7400 Tübingen, Federal Republic of Germany.

${ }^{\circ}$ Present address: Department of Biological Sciences, Stanford University, Stanford, CA 94305.

Copyright (C) 1990 Society for Neuroscience $0270-6474 / 90 / 082601-13 \$ 03.00 / 0$ neurons, contribute significantly. The pattern of axonal branching of subplate neurons also implies that information conferred to subplate neurons may be relayed, in turn, to the neurons of cortical layer 4 . Finally with the death of subplate neurons, the geniculocortical axons leave the subplate and invade the cortical plate to innervate directly the neurons of layer 4 . Thus, subplate neurons may function as a crucial, but transient synaptic link between waiting geniculocortical axons and their ultimate target cells in the cortex.

In the development of the mammalian cerebral cortex, the first synapses appear during early fetal life within a transient structure known as the subplate, located just below the cortical plate (Molliver et al., 1973; Kostovic and Molliver, 1974; Chun and Shatz, 1988a). The subplate is populated by neurons that are the first to be generated, and in the cat subplate neurons are born about 1 week before the neurons of the adult cortical layers (Luskin and Shatz, 1985b). These neurons are immunoreactive for neuropeptides and for the neuron-specific marker microtubule-associated-protein 2 (MAP2), and they receive synaptic contacts-all hallmarks of mature neurons-weeks before neurons of the cortical plate have similar characteristics (Kostovic and Rakic, 1980; Chun et al., 1987; Chun and Shatz, 1989a, b). Ncarly the cntirc population of subplate neurons is then eliminated by cell death shortly after birth in the cat (Valverde and Facal-Valverde, 1987; Chun and Shatz, 1989b).

In contrast to our knowledge of their morphology and transmitter phenotypes, little is known about the function of subplate neurons. One possibility is that they may have a special relationship with ingrowing axonal systems. For example, in the cat the thalamocortical axons are known to "wait" for several weeks in the subplate prior to invading the cortical plate and contacting their ultimate target neurons in layer 4 (Shatz and Luskin, 1986). Evidence that subplate neurons may interact with waiting axons and help them recognize their correct cortical targets during development has been obtained recently by ablating subplate neurons during early fetal life. Following a subplate lesion, axons that would normally grow into the cortical plate fail to do so and instead grow past the region of the ablation toward abnormal cortical target areas (Ghosh et al., 1989).

The presence of synapses on subplate neurons during the waiting period suggested that there might be functional interactions between the waiting axons and subplate neurons. These interactions might be important for thalamic axons to select an appropriate cortical target. To investigate this suggestion, we have examined whether subplate neurons receive functional synaptic inputs from axons that run in the white matter, and whether, in turn, the subplate neurons might be capable of relaying this 
input to neurons in the developing cortical plate. Living slices through the cerebral wall of fetal and neonatal visual cortex were prepared for intraccllular recording and tracer injection in vitro. We concentrated on studying the 3 -week period between embryonic day 50 (E50) and postnatal day 9 (P9) in the cat, when axons first wait below, and then invade the cortical plate (Shatz and Luskin, 1986). By P9, the subplate neurons have begun to disappear in large numbers (Chun and Shatz, 1988b). Our results show that subplate neurons participate in functional synaptic microcircuits: they are postsynaptic to axons in the white matter and send axons into the cortical plate, suggesting that they may be presynaptic to cortical cells as well.

\section{Materials and Methods}

Seventeen cat brains between the ages of E50 and P9 were analyzed. The fetal age was determined to within $\pm 24 \mathrm{hr}$ by timed breedings in our cat colony (Luskin and Shatz, 1985b).

Surgical procedure. Complete surgical procedures have been described previously (Luskin and Shatz, 1985b; Chun and Shatz, 1988b). Fetal animals were delivered by ccsarcan scction. Anesthesia of mother cats was induced by intramuscular injection of ketamine $(20 \mathrm{mg} / \mathrm{kg})$ and acepromazine $\left(0.2 \mathrm{mg} / \mathrm{kg}\right.$ ) and maintained by halothane $(1-2 \%)$ in $\mathrm{O}_{2}$. Neonatal kittens were anesthetized by intraperitoneal injections of nembutal $(35 \mathrm{mg} / \mathrm{kg})$. Animals were decapitated and the brain was removed and immersed in ice-cold Ringer's solution (for composition, see McCormick and Prince, 1987).

Slicing procedure. Living slices through the telencephalon containing the primary visual cortex were cut in the coronal plate on a vibratome at high amplitude and very low speed. The thickness of the sections varied from $500 \mu \mathrm{m}$ in fetal animals to $400 \mu \mathrm{m}$ in postnatal kittens. Kynurenic acid was usually added to the Ringer's solution during cutting (final concentration $1 \mathrm{~mm}$ ) to counteract the neurotoxic effects of released excitatory amino acids (Watkins and Olverman, 1987; Choi et al., 1988). Cut sections were trimmed into smaller pieces containing the visual cortex and part of the optic radiations and were then transferred into an interface-type recording chamber. The chamber was perfused with warmed $\left(37.5^{\circ} \mathrm{C}\right)$ and oxygenated Ringer's solution at a rate of ca. $1.5 \mathrm{ml} / \mathrm{min}$. Warmed, humidified carbogen $\left(95 \% \mathrm{O}_{2}, 5 \% \mathrm{CO}_{2}\right)$ was constantly blown over the sections. Recording was begun $1.5-2 \mathrm{hr}$ after sectioning.

Recording procedure. Recording electrodes were pulled on a Brown Flaming P77 horizontal micropipette puller from $1.2 \mathrm{~mm}$ medium walled glass tubes containing microfilaments. The tip diameters of the electrodes were less than $0.5 \mu \mathrm{m}$ as judged under a light microscope. To permit later identification of recorded neurons, electrodes were backfilled with biocytin (biotinylated lysine, Sigma \#B4261) which was dissolved at $2 \%$ concentration in $2 \mathrm{M}$ potassium acetate, buffered to $\mathrm{pH}$ 7.4. The biocytin solution was made fresh in the morning of every experiment. Details of the biocytin technique have been published previously (Horikawa and Armstrong, 1988). The DC-resistances of the electrodes ranged from 120 to $190 \mathrm{M} \Omega$. Recording electrodes were placed into the subplate at a distance of $0.5-1 \mathrm{~mm}$ from the stimulating electrodes. Subplate cells were penetrated by passing short current pulses (10-20 msec in duration) through the electrode tip using the modified buzzer provided with the intracellular amplifier (Getting $5 \mathrm{~A}$ ). This buzzer produced $A C$ oscillations with $10 \mathrm{msec}$ duration and variable frequency. After impalement, hyperpolarizing current was usually injected briefly to facilitate "sealing" of the cell membrane. Electrical shocks (50 $\mu$ sec duration) were applied to the optic radiations by bipolar stimulating electrodes of etched and insulated tungsten wires connected to a voltage source via stimulus isolation units. In fetal life, as in the adult, axons from visual thalamic nuclei such as the LGN run in a tight bundle, the optic radiations (see Shatz and Luskin, 1986). Low frequency stimulation $(0.5 \mathrm{~Hz}$ for postnatal slices, $0.2 \mathrm{~Hz}$ for fetal slices) was chosen to protect the delicate tissue from transmitter depletion and synaptic fatigue. Synaptic and antidromic responses from the neurons as well as their responses to direct current injection were visualized on an oscilloscope, digitized, stored on videotape, and later analyzed. The latency and duration of synaptic signals were measured and the response patterns to current injection were determined. Membrane input resistances were calculated from the slopes of the current-voltage relations.

Histological procedure. After the acquisition of electrophysiological data, biocytin was iontophoresed into cells using depolarizing rectangular current pulses of 0.8-1.5 nA. Higher amplitudes proved to be harmful to the neurons as judged by a loss in resting membrane potential and subsequent beading of processes. The duration of the pulses was $300-500 \mathrm{msec}$ at a frequency of $1-2 \mathrm{~Hz}$. During injection, the membrane potential was constantly monitored to check the quality of the intracellular recording. Injection was stopped either when the recording deteriorated to less than $-20 \mathrm{mV}$ resting potential or after $15 \mathrm{~min}$. To avoid confusion, no more than 4 cells were injected in each slice, and the injection sites were noted and kept at least $400 \mu \mathrm{m}$ apart. About 20 min after completion of the last injection into a neuron, the slice was fixed in $4 \%$ paraformaldehyde (pH 7.4) and kept overnight at $4^{\circ} \mathrm{C}$. Slices were embedded in gelatin-albumin (45 gm egg albumin and $0.75 \mathrm{gm}$ gelatin in $150 \mathrm{ml} 0.1 \mathrm{M}$ phosphate buffer hardened with glutaraldehyde) and recut on a vibratome at $60-100 \mu \mathrm{m}$. They were collected in phosphate-buffered saline (PBS, $0.9 \% \mathrm{NaCl}$ in $0.01 \mathrm{~m}$ phosphate buffer, $\mathrm{pH}$ 7.4) and incubated overnight in avidin-HRP (Vector Labs; dilution 1: $100)$. Triton $X 100(0.25 \%)$ was included to make the cell membranes more permeable, and bovine serum albumin (2\%) was added to decrease the background staining. The avidin-HRP incubation was followed by a hydrogen peroxide reaction using diaminobenzidine (DAB, Sigma) as the chromogen. Sections were thoroughly washed in PBS, mounted on slides, air-dried, dehydrated, and coverslipped. Labeled cells were reconstructed under a microscope with the aid of a drawing tube. Axons were identified by their uniform diameter, which was of fine caliber; a single axon usually emerged from the cell body or a primary dendrite and often branched several times to form many collaterals. Dendrites were thicker, tapering in diameter, and frequently resembled MAP2 immunoreactive processes previously observed in subplate neurons (Chun and Shatz, 1989a). Sections containing labeled cell processes were decoverslipped, rehydrated, and counterstained with cresyl violet to permit the localization of borders between the cortical plate and the subplate (for criteria, see Luskin and Shatz, 1985a; Chun and Shatz, $1989 \mathrm{a}$ ), and also identification of the forming cortical layers.

\section{Results}

The results will be presented in 3 sections. In the first section, the general physiological properties of subplate neurons will be described. Then we will focus on the detailed morphological and physiological features of subplate neurons at 4 different ages, from E50 to P9. Finally, the detailed morphology of subplate neurons and its relation to the cortical plate will be examined. In all cases, examples are drawn from neurons that have been recorded intracellularly and subsequently injected with biocytin to identify them as subplate ncurons bascd on their location.

\section{Physiological properties of subplate neurons}

Stable intracellular microelectrode recordings were possible as early as E50, about 2 weeks before birth (gestation is $65 \mathrm{~d}$ in the cat). Between E30 and E50, axons from the thalamus arrive within the subplate, where they accumulate and wait for 2-3 weeks before they grow into the cortical plate (Shatz and Luskin, 1986). Intracellular recordings indicate that during the waiting period, subplate neurons can receive excitatory postsynaptic potentials from electrical stimulation of the optic radiations. An example of the results from one experiment performed at E50 are shown in Figure 1, where responses to 3 different stimulus intensities are superimposed. At the lowest intensity, only a small EPSP is evoked to single shock stimulation. With higher intensity, the EPSP amplitude increases and, finally, a single spike results. A further increase of the stimulus intensity fails to evoke additional spikes (not shown). Although the latency to the onset of the EPSP is long $(6.4 \mathrm{msec})$, we believe that the EPSPs represent monosynaptic potentials for several reasons. First, increasing the stimulus strength does not shorten the latency to the onset of these EPSPs, even though the amplitude of the EPSP does grow. This suggests that while there is spatial 
summation of many synapses onto subplate neurons, they all have the same latency. A second reason is that at this early fetal age, all axons are unmyelinated and conduction velocities are extremely slow (ca. $0.25 \mathrm{~m} / \mathrm{sec}$; E. Friauf, unpublished observation). Thus, at a given distance of $1 \mathrm{~mm}$ between stimulation electrodes and recording site, the conduction time alone requires about $4 \mathrm{msec}$. Finally, current-source-density analysis of the responses in equivalent slices to electrical stimulation of the optic radiation indicates that the shortest detectable latencies for synaptic excitation are found within the subplate and average $5.3 \mathrm{msec}$ (Friauf et al., 1989; E. Friauf and C. J. Shatz, unpublished observations).

It is noteworthy that neither the cell in Figure 1 nor any other subplate neuron recorded received detectable polysynaptic, long latency excitation from single shock stimulation of the optic radiations. It is conceivable that high frequency stimulation might have revealed such inputs, but in fact we found that such stimulation caused rapid fatigue of the monosynaptic response and therefore we typically used very low frequency stimulation ( $0.5 \mathrm{~Hz}$ after birth, $0.2 \mathrm{~Hz}$ before birth).

The majority of recorded subplate neurons were not spontaneously active and had stable resting potentials that exceeded $-30 \mathrm{mV}$ and were as great as $-70 \mathrm{mV}$. All had very high input resistances, which ranged from $52 \mathrm{M} \Omega$ to $204 \mathrm{M} \Omega$, with a mean of $105 \mathrm{~m} \Omega$. These high input resistances suggest that we recorded from relatively healthy neurons despite the occasional presencc of low resting potentials. The current-voltage relations of all cells were linear with no, or only a small, outward rectification (cf Fig. 5B).

When depolarized directly by current injection beyond spike threshold, subplate neurons demonstrated 3 different spiking patterns. These 3 categories are illustrated in Figure 2 for 3 different neurons recorded in neonates. Cells of the first type ( 25 of 39 cells) responded with a brisk spike at the beginning of the current pulse; however, a second spike was never elicited,

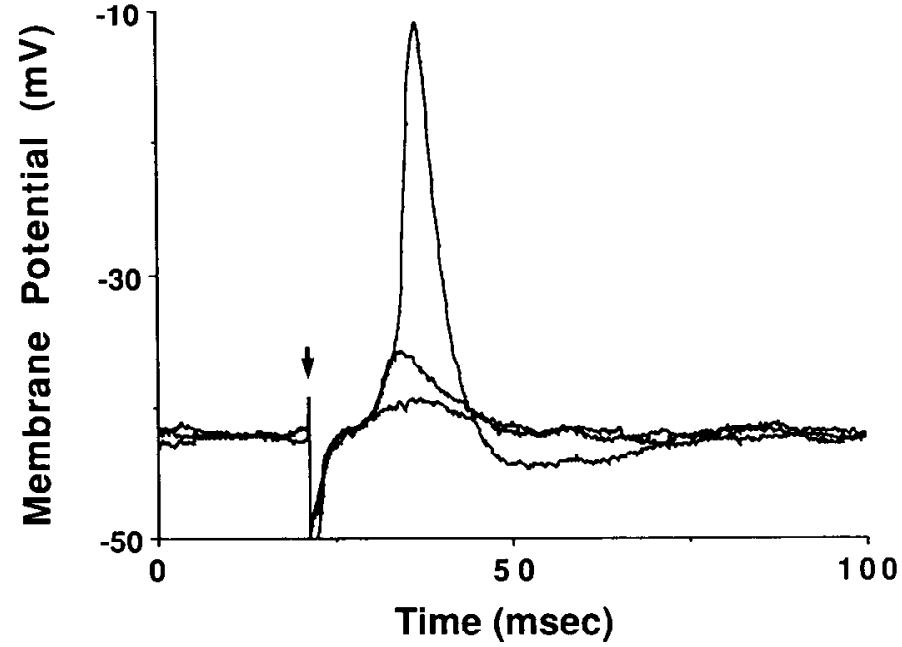

Figure 1. Intracellular responses of a morphologically identified subplate neuron at E50. Responses to stimulation of fibers in the optic radiations at 3 different stimulus intensities are superimposed. Stimulus artifact is indicated by the arrow. Note the steep rising phase and the constant latency of the EPSPs and the action potential, which are indicative of a monosynaptic response.

regardless of the current strength (Fig. 2A). This category is referred to as "single spiking." Units in the second category ( 8 of 39 cells) fired more than one spike to applied current but exhibited pronounced frequency adaptation, thereby resulting in spike failure within about $100 \mathrm{msec}$ of current onset (Fig. $2 B)$. We therefore refer to cells in this category as "adapting." Finally, units in the third category ( 6 of 39 cells) exhibited maintained firing during current injection, with relatively little frequency adaptation (Fig. 2C). This type of firing was previously described in adult cortical neurons as "regular spiking" (McCormick et al., 1985). In our sample of cells, no adapting

Table 1. Physiological characteristics of morphologically identified subplate neurons ${ }^{a}$

\begin{tabular}{|c|c|c|c|c|c|c|c|c|}
\hline Age & $\begin{array}{l}\text { Resting } \\
\text { potential } \\
(\mathrm{mV})\end{array}$ & $\begin{array}{l}\text { EPSP } \\
\text { latency }^{b} \\
\text { (msec) }\end{array}$ & $\begin{array}{l}\text { EPSP } \\
\text { duration } \\
(\mathrm{msec})\end{array}$ & $\begin{array}{l}\text { Antidromic } \\
\text { spike }\end{array}$ & $\begin{array}{l}\text { Input } \\
\text { resistance } \\
(\mathrm{M} \Omega)\end{array}$ & Spiking pattern & Morphology & $\begin{array}{l}\text { Figure } \\
\text { in which } \\
\text { cell is } \\
\text { illus- } \\
\text { trated }\end{array}$ \\
\hline E50 & -42 & 6.4 & 21.1 & No & - & - & Inverted pyramid & 1 \\
\hline E52 & -42 & 5.6 & 26.2 & Yes & 159 & Single & Multipolar & 3 \\
\hline E55 & -50 & 6.0 & 46.0 & Yes & 159 & Single & Inverted pyramid & 4 \\
\hline E55 & -38 & 4.2 & 58.0 & Yes & - & - & Multipolar & - \\
\hline E56 & -46 & 3.5 & 11.2 & Yes & - & - & Inverted pyramid & - \\
\hline E58 & -38 & 2.5 & 17.0 & Yes & - & - & Inverted pyramid & - \\
\hline P1 & -51 & 5.9 & 22.9 & Yes & 100 & Adapting & Inverted pyramid & - \\
\hline P1 & -36 & 4.8 & 27.0 & Yes & - & Single & Bipolar & - \\
\hline $\mathrm{Pl}$ & -30 & 4.1 & 25.25 & Yes & 185 & Single & Bipolar & - \\
\hline P3 & -44 & 3.9 & 74.7 & Yes & 56 & Regular & Inverted pyramid & - \\
\hline P3 & -62 & 4.6 & 43.0 & Yes & 70 & Adapting & Multipolar & - \\
\hline P3 & -43 & 3.0 & 16.5 & Yes & 57 & Single & Inverted pyramid & - \\
\hline P4 & -52 & 3.9 & 59.0 & No & 180 & Regular & Multipolar & - \\
\hline P4 & -64 & 4.0 & 55.3 & Only direct & 204 & Single & Inverted pyramid & - \\
\hline P4 & -58 & 4.6 & 21.5 & Yes & 200 & Single & Inverted pyramid & 5 \\
\hline P9 & -39 & 5.4 & 15.0 & No & - & Single & Bipolar & 6 \\
\hline
\end{tabular}

a This table represents a selected subpopulation of all cells studied. These cells had resting potentials greater than $-30 \mathrm{mV}$ and also were well filled with biocytin.

"Latency to onset of EPSP measured. 


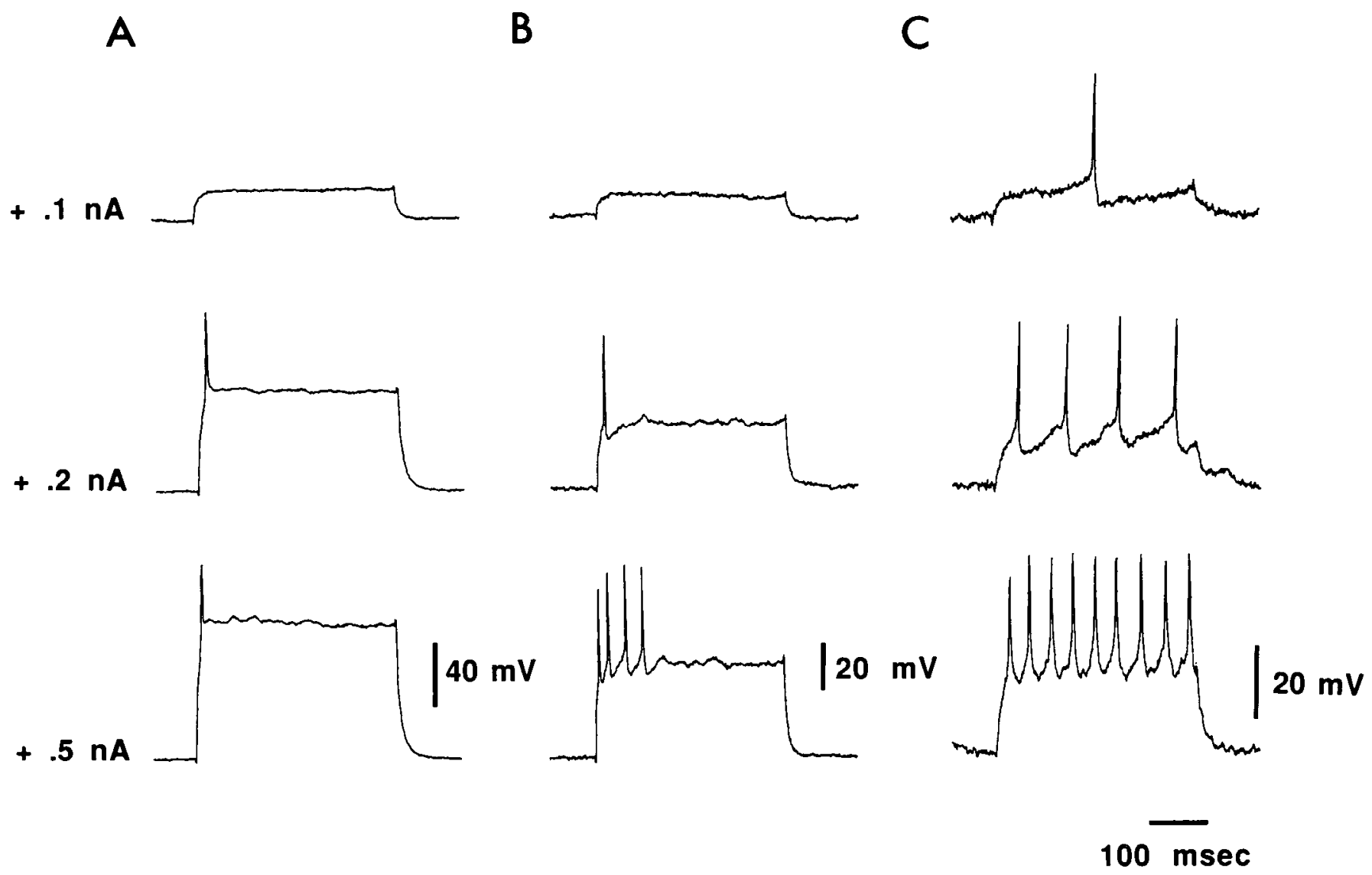

Figure 2. Three categories of spiking patterns evoked by intracellular current injection in subplate neurons. $A$ and $B$ are from neurons at $\mathrm{P} 3$, and $C$ is from a neuron at P4. A, Single spiking neurons displayed only one action potential in response to suprathreshold current pulses, regardless of the amount of current injected. B. Adapting neurons fired more than one action potential if depolarized above threshold, but the spike frequency adapted rapidly and spiking ceased within $100 \mathrm{msec}$. C, Regular spiking neurons continued to fire during the depolarizing current pulse and their firing frequency increased with increasing depolarization. Of 39 subplate neurons analyzed, 25 were single spiking, 8 were adapting, and 6 were regular spiking.

or regular spiking subplate neurons were encountered before birth. While this observation suggests that cells with these firing patterns may not be present prenatally, our small sample size precludes a definitive conclusion (see Table 1).

\section{Morphological and physiological features of subplate neurons}

As mentioned above, geniculocortical axons during development wait within the subplate for 2-3 weeks before they begin to invade the deep cortical layers. Ingrowth of axons into the deep cortical layers begins between about E50 and E55, the time that their targets, the layer 4 cortical neurons, complete their migrations. Geniculocortical axons finally invade and branch within layer 4 during postnatal life. Concurrently, subplate neurons die off in large numbers. We wished to examine whether subplate neurons participate in functional synaptic circuits during these different developmental periods, and if so, whether there are changes in their synaptic connectivity. Therefore, 2 questions were addressed: (1) Do subplate neurons receive monosynaptic excitation during all these periods? (2) Does the morphology of subplate neurons suggest that they may have synaptic relationships with cortical plate neurons?
Properties of subplate neurons during the waiting period of geniculocortical axons (E50-E52)

Between E50 and E52, 12 subplate neurons were recorded intracellularly and 7 were also injected with biocytin. Of those driven by stimulation of the optic radiations, 10 exhibited monosynaptic EPSPs and 8 could be antidromically activated. Of the cells recovered for anatomy, few $(n=3)$ were well enough injected to be able to make a detailed statement about their morphology. However, the somata of all were definitively located in the subplate. The 3 well-filled subplate neurons did not form a homogeneous morphological group. One cell resembled an inverted pyramidal cell, one neuron was multipolar (Fig. $3 A$ ), and a third was pyramidal in shape. This observation is not surprising in view of the well-known morphological heterogenity of subplate neurons (Marin-Padilla, 1971; Wahle et al., 1987; Chun and Shatz, 1989a).

As shown in the previous section and in Figure 3, subplate neurons during the waiting period can receive functional excitatory inputs from stimulation of the optic radiations. An example of a subplate neuron injected with biocytin at E52 is shown in Figure $3 A$. The soma of the cell and many of its 

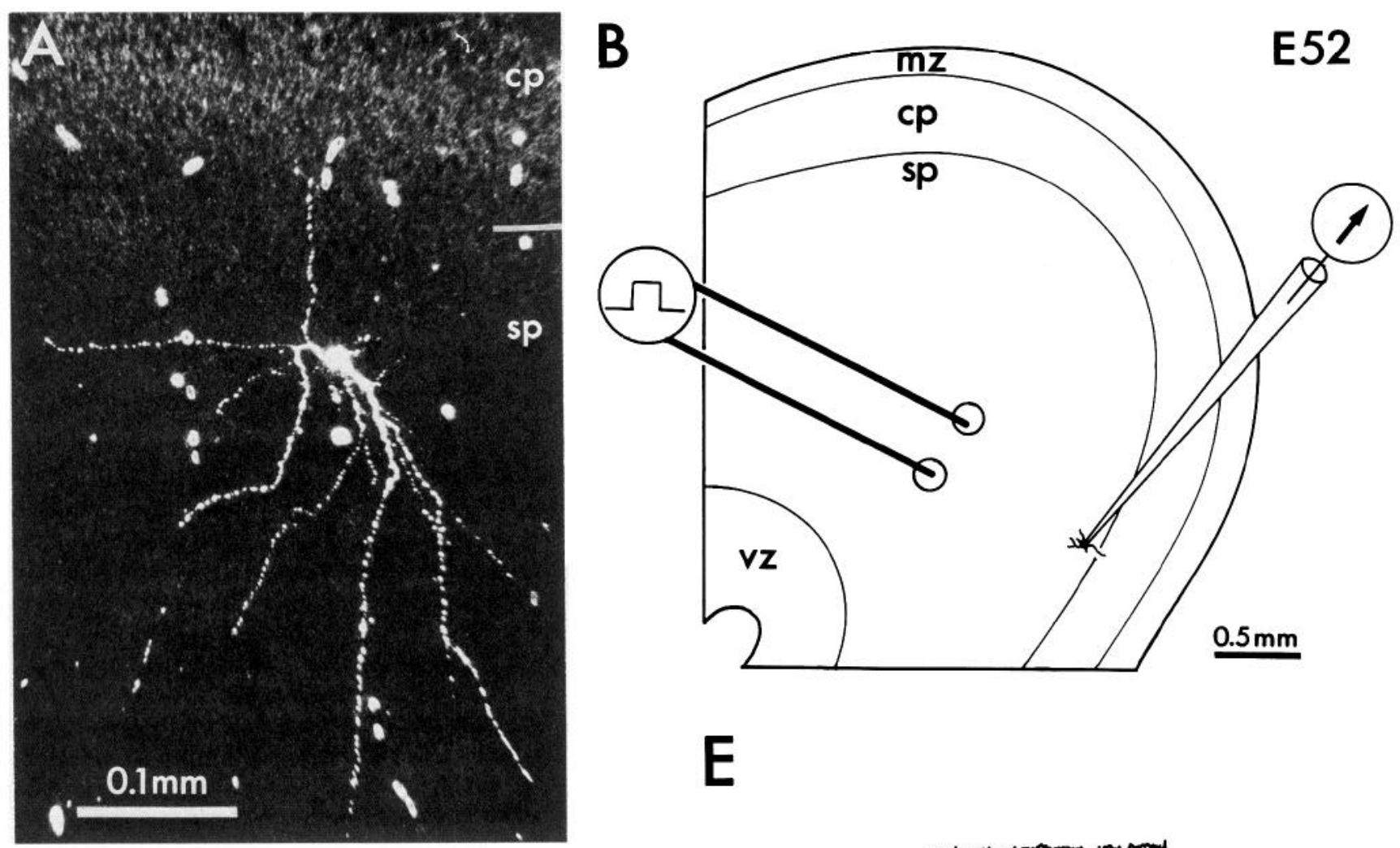

C
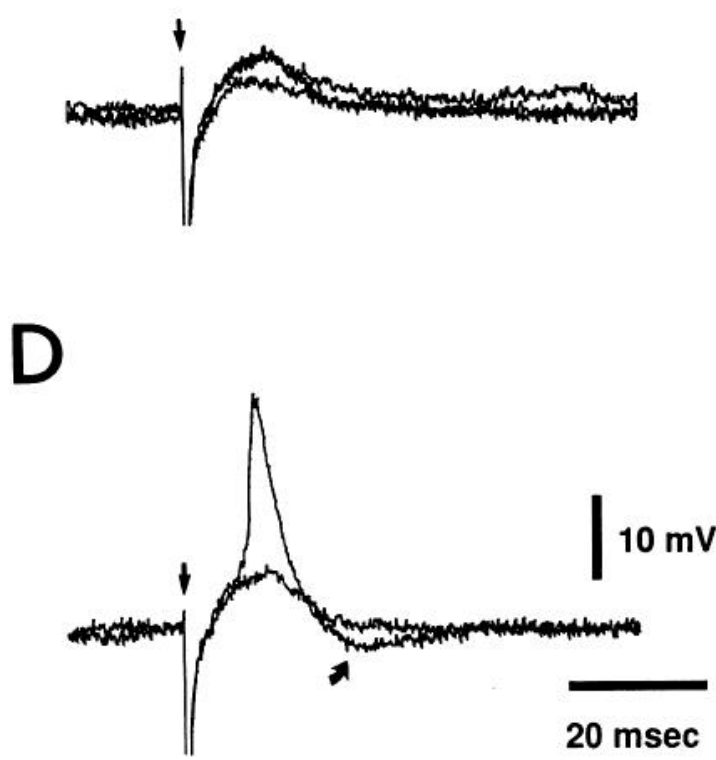

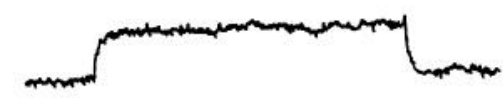

$+.15 \mathrm{nA}$

$+.2 \mathrm{nA}$

E
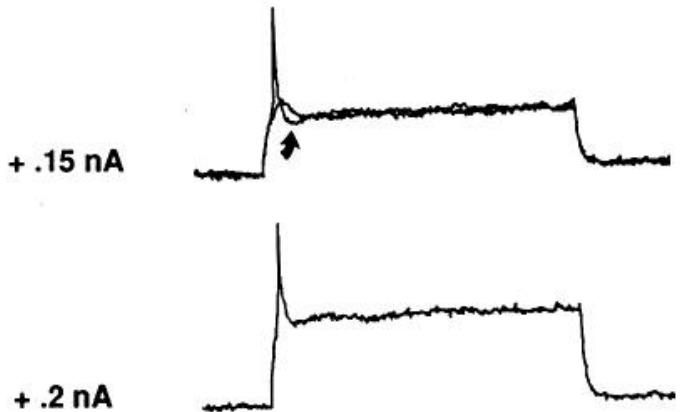

$+.3 \mathrm{nA}$

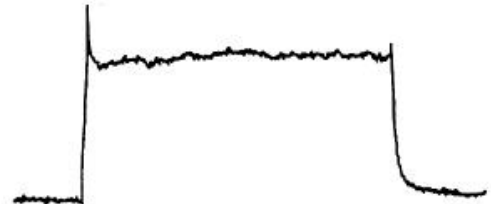

$20 \mathrm{mV}$

Figure 3. Morphology and physiology of a subplate neuron at E52. A, Dark-field photomicrograph of the neuron injected with biocytin, revealing the border between the cortical plate and the subplate. Most of the cell's dendrites are located within the subplate; one process enters the cortical plate. $B$, Cartoon illustrating the location of the neuron in $A$ and the approach used in the physiological studies. The stimulating electrode shown here was used to apply electrical shocks to the optic radiations. Subplate neurons were impaled with biocytin-filled micropipettes, recorded from, and iontophoretically injected with biocytin. $C$, Three superimposed EPSPs resulting from stimulation of the optic radiations (arrow). $D$, EPSP and synaptic spike elicited at higher stimulus amplitude. Note the afterhyperpolarization following the action potential (curved arrow). E, Responses of the neuron to direct current injection. Current injected at straddling threshold $(+0.15 \mathrm{nA})$ elicits a single action potential. Increasing current amplitude continues to elicit only a single spike; thus this cell is a single spiking neuron. In this and all following figures: $c p$, cortical plate; $m z$, marginal zone; $s p$, subplate; $v z$, ventricular zone. 


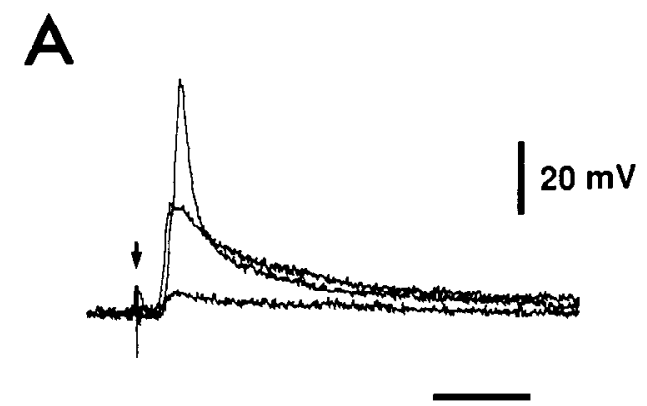

$20 \mathrm{msec}$
Figure 4. Physiology and morphology of a subplate neuron at E55. $A$, EPSPs or a spike results following stimulation of the optic radiations (arrow) at different intensities. $B$, Biocytin injection revealed an inverted pyramid with an axon collateral coursing toward the ventricular zone and another collateral that looped to enter the cortical plate and terminated in the marginal zone (future layer 1).

processes are located just below the cortical plate (Fig. $3 B$ ), in the subplate as previously defined (Kostovic and Rakic, 1980; Luskin and Shatz, 1985a; Chun and Shatz, 1988b, 1989a). One neuronal process ascends and enters the cortical plate with no apparent collateral system. However, the morphological reconstruction of the cell is incomplete because the $500 \mu \mathrm{m}$ thick slice did not contain the entire ascending process. Furthermore, cells at these very early ages were difficult to impale and hold stable for a sufficiently long time to inject biocytin, and those that were
B

E 55

cp

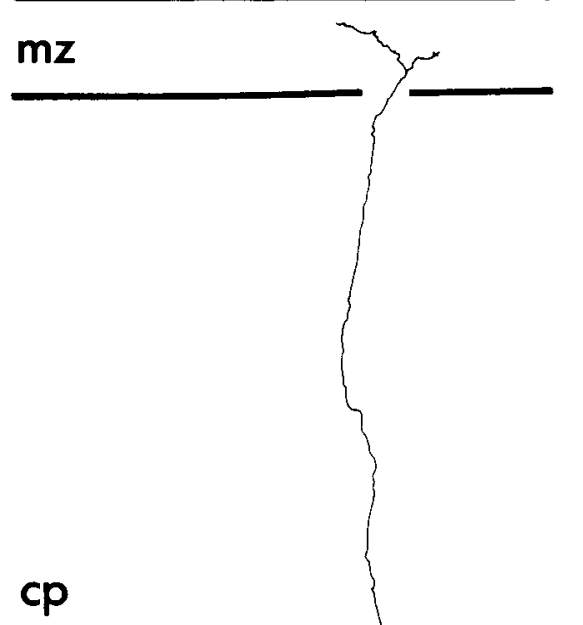


pattern of this neuron to intracellular injection of depolarizing current was of the single spiking variety (Fig. $3 E$ ).

Subplate neurons during the onset of thalamic axon ingrowth into the cortical plate (E55-E58)

Between E55 and E58, we examined 17 subplate neurons, 13 of which could be synaptically and 10 antidromically driven. At these older ages, many more cells $(n=13)$ were well filled following intracellular biocytin injections. Particularly noteworthy was the fact that axon collaterals of many subplate neurons not only ramified within the subplate, but also entered the cortical plate (see Fig. 4B). The dendritic morphology of the cells studied was heterogeneous, with $9(69 \%)$ inverted pyramids, $3(23 \%)$ multipolar, and $1(8 \%)$ bipolar in shape.

Between E55 and E58 subplate neurons continue to receive monosynaptic input following electrical stimulation of the white matter. An example of the responses of a subplate cell at F55 is shown in Figure 4. Monosynaptic EPSPs and spikes, as well as antidromic action potentials (not shown), could be elicited from stimulation of the optic radiations (Fig. $4 A$ ). Biocytininjection revealed an elaborate morphology (Fig. $4 B$ ). The shape of the neuron resembles an inverted pyramidal cell with many dendrites directed downward within the subplate toward the ventricular zone. A simple axon also descends deep within the subplate and branches to elaborate collaterals (Fig. 4B). The axon also branches to send a collateral that loops back to enter the cortical plate and terminates in the marginal zone. Few, if any, branches are given off in the cortical plate. Thus, this neuron has the inverted pyramidal cell morphology considered typical of many subplate neurons, previously studied by Golgi and immunohistochemical techniques both in fetal animals (MarinPadilla, 1971; Chun et al., 1987; Chun and Shatz, 1989a) and in neonatal animals (Valverde and Facal-Valverde, 1987, 1988; Wahle and Meyer, 1987; Wahle et al., 1987; Chun and Shatz, 1989b).

Subplate neurons as axons arrive in layer 4 (P1-P4). Intracellular studies of subplate neurons between P1 and P4 were the most successful of all ages studied. We recorded from 43 cells and injected 38 with biocytin, 27 of them being sufficiently well filled to permit morphological analysis. Fourteen $(52 \%)$ of the subplate cells were inverted pyramids, $5(18 \%)$ were regular pyramids, 4 (15\%) were identified as bipolar, and $4(15 \%)$ multipolar in shape (see Figs. $5 \mathrm{~A}, 8$, and 9).

As at earlier ages, so too at $\mathrm{P} 4$, subplate neurons generate monosynaptic EPSPs and synaptic spikes following electrical stimulation of the optic radiations. Overall 39 neurons could be stimulated synaptically and 35 showed antidromic spikes. Physiological and morphological properties of one subplate neuron studied at P4 are shown in Figure 5. In this neuron, the similar latencies of the EPSP elicited at low stimulus amplitude and the synaptic spike elicited at higher amplitude (Fig. 5C) illustrate once again the likely monosynaptic character of the response. An antidromic spike could be evoked only at higher stimulus amplitude (Fig. 5D), for most subplate neurons 2-4 times that required to elicit an orthodromic EPSP. This finding indicates that the threshold for activation of the different axons in the white matter is lower than that for the efferent axons originating from the subplate neurons themselves. Antidromic spikes were shorter in latency and did not show any deflection in rising phase. The current-voltage relation of the cell was linear (Fig. $5 B$ ), and the cell was characterized as a single spiking neuron (not shown).
Biocytin-injection revealed that this neuron was an inverted pyramidal cell (Fig. $5 \mathrm{~A}$ ). As at earlier ages, the neuron has a set of branching axon collaterals in the subplate and one collateral that traverses the cortical plate to terminate within the marginal zone. However, in contrast to axons at earlier ages, this collateral branches not only in the subplate and the marginal zone but also within the upper part of cortical plate, which at this early neonatal age corresponds primarily to cortical layer 4 . Layers 2 and 3 are only partially formed since the cells are still in the process of migrating (Shatz and Luskin, 1986).

Subplate neurons during the peak period of cell death (P7-P9). At these later postnatal ages, it again was quite difficult to impale subplate neurons, presumably due to the tremendous diminution in the subplate cell number and density during the first postnatal week (Chun and Shatz, 1989b). Only 6 cells were recorded intracellularly, all of which received monosynaptic FPSPs and could be antidromically activated by stimulation of the optic radiations. Four cells were sufficiently biocytin-filled for morphological analysis. Two cells were inverted pyramids, 1 was multipolar, and 1 was bipolar.

The morphological and physiological characteristics of a subplate neuron at P9 are shown in Figure 6. The dendritic structure of this neuron is essentially bipolar, and, as at earlier postnatal ages, a single axon gives rise to an extensive set of collaterals that arborize both within the subplate and within the cortical plate. Many collaterals given off within the cortical plate are tipped with growth cones, suggesting that this particular axon is still undergoing considerable modification (Fig. 6A). Collaterals within the cortical plate could not be entirely reconstructed since many exited the $450 \mu \mathrm{m}$ thick slice.

This cell received monosynaptic EPSPs from stimulation of the radiations, with action potentials evoked at higher stimulus strengths (Fig. 6B). The action potentials were followed by a distinct afterhyperpolarization. Like the majority of all subplate neurons, this cell demonstrated a single spiking pattern to intracellular current injection (Fig. 6C).

To summarize so far, our findings indicate that as early as E50, subplate neurons receive functional synaptic inputs from stimulation of the optic radiations. These inputs remain until at least P9. During this period, the physiological properties of subplate neurons sampled did not undergo major changes. For example, resting potentials and input resistances of well-impaled cells were not age-dependent (Table 1). In addition, the EPSP latency did not change significantly from an average of $5.3 \mathrm{msec}$ at E50 (Fig. 7). However, these data have not been corrected for somewhat variable distances between recording and stimulating clectrodes, which ranged from 0.5 to $1 \mathrm{~mm}$.

\section{Subplate neuron morphology and its relation to the cortical plate}

As noted in the preceding sections, it was common to find that subplate neurons have axonal collaterals not only within the subplate but also within the cortical plate. Additional examples are shown here in Figures 8 and 9. All of the illustrated neurons received monosynaptic EPSPs following electrical stimulation of the optic radiations. The number and complexity of axon collaterals within the cortical plate appeared to increase with age. In fetal life, usually only a single axon collateral entered and traversed the cortical plate to give off a few branches restricted to the marginal zone. In contrast, by birth, many cells extended axons into the cortical plate and these collateralized extensively within layer 4 (Figs. $5 A ; 8 ; 9, C, D$ ). While most 
A
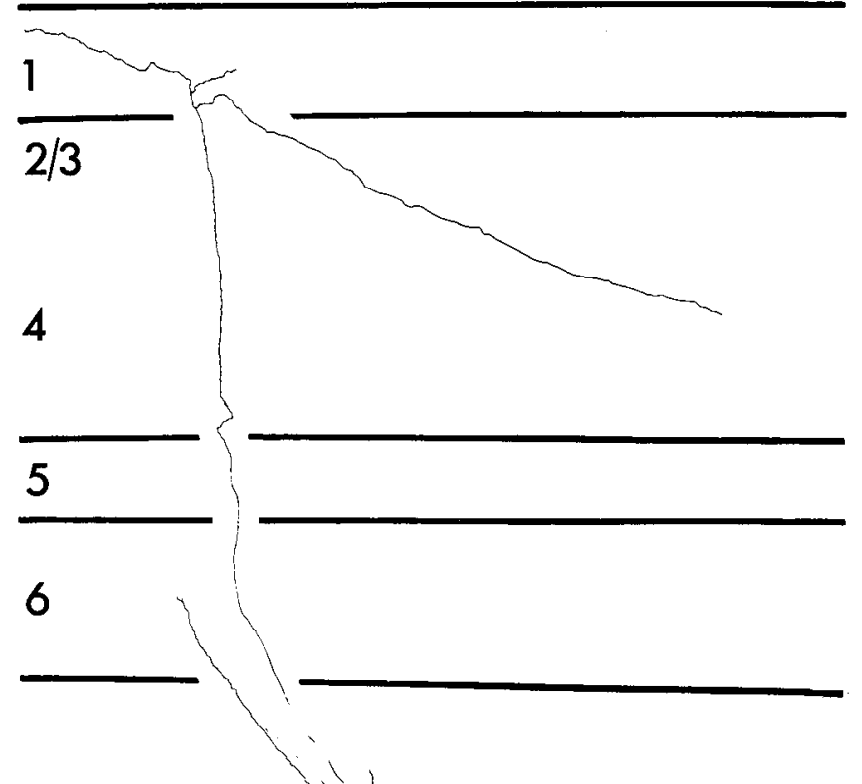

sp

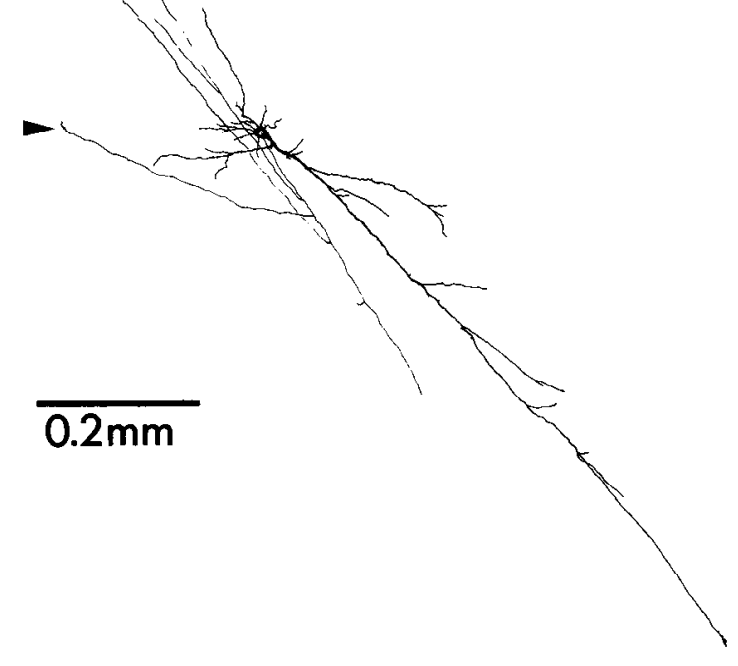

B
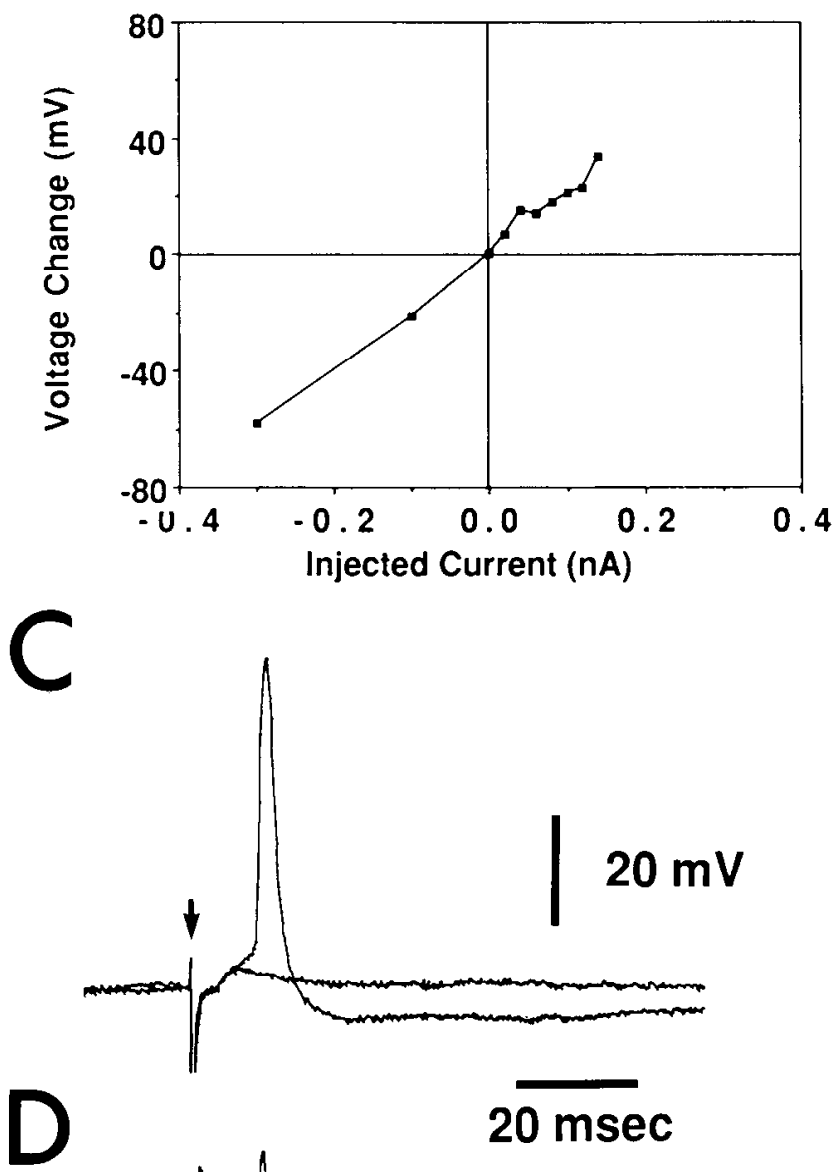

D
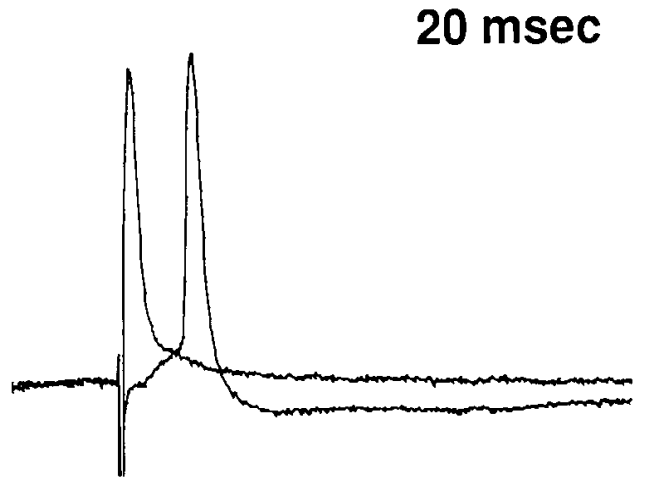

Figure 5. Morphology and physiology of a subplate neuron at P4. A, The inverted pyramid gives off an axon that arborizes and enters the cortical plate, with terminal branches in the marginal zone (layer 1) and in layer 4. Note that one of the axon collaterals in the subplate ends in a growth cone (arrowhead). B, Current-voltage relation for the same neuron. Each point corresponds to the change in membrane potential at the end of a $200 \mathrm{msec}$ current pulse applied from resting potential $(-58 \mathrm{mV})$. The linear relationship indicates a lack of inward rectification. Calculated input resistance is $200 \mathrm{M} \Omega$. C. Synaptic responses elicited by electrical stimulation of the optic radiations (arrow) at different intensities. $D$, At even higher stimulus intensity, an antidromic spike is evoked, blocking the synaptic spike. Calibration bars refer to $C, D$.

subplate neurons had collaterals in the cortical plate that were radially restricted (e.g., Fig. 9, $C, D$ ), a few had widespread collaterals (Figs. $5 A, 8$ ) that could extend over $1 \mathrm{~mm}$ tangentially. These observations suggest that at least some subplate neurons may undergo continued axonal growth into postnatal life, a suggestion supported by the finding that growth cones are frequently evident at the tips of axon collaterals even at F55 (Fig. 4) and at P9 (Fig. 6).

In contrast to the axonal arborizations, the major portion of the dendritic tree of most of the subplate neurons studied was confined to the subplate itself. Well-filled biocytin-injected sub- plate neurons could be divided into 4 broad morphological classes: inverted pyramids (26 of 47), multipolar ( 9 of 47), bipolar (6 of 47), and pyramids (6 of 47). Examples of inverted pyramidal cells are shown in Figure $4(\mathrm{P} 4)$, Figure $5(\mathrm{P} 1)$, and Figure $9, A$ and $B$ (E55 and P1). Multipolar cells are shown in Figure $3 A$ (E52) and Figure $8(\mathrm{P} 1)$ and bipolar cells are illustrated in Figures 6 and $9 C$ (P9 and P1). Thus, there was no tendency for subplate neurons with a particular morphology to be encountered preferentially at any given age (see also Table 1).

Typical pyramidal neurons were seen in 6 cases. All of the 


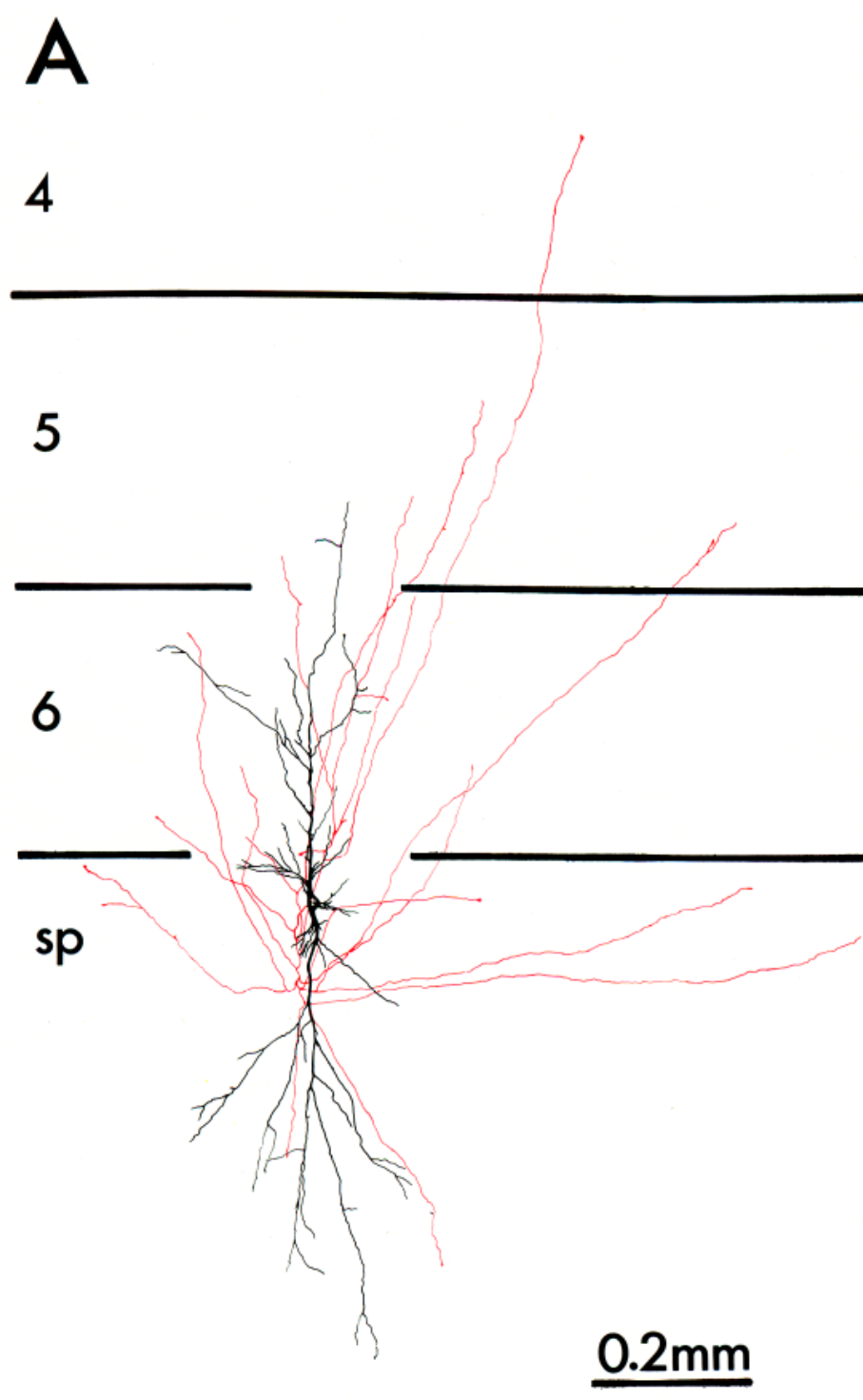

\section{B}

P9

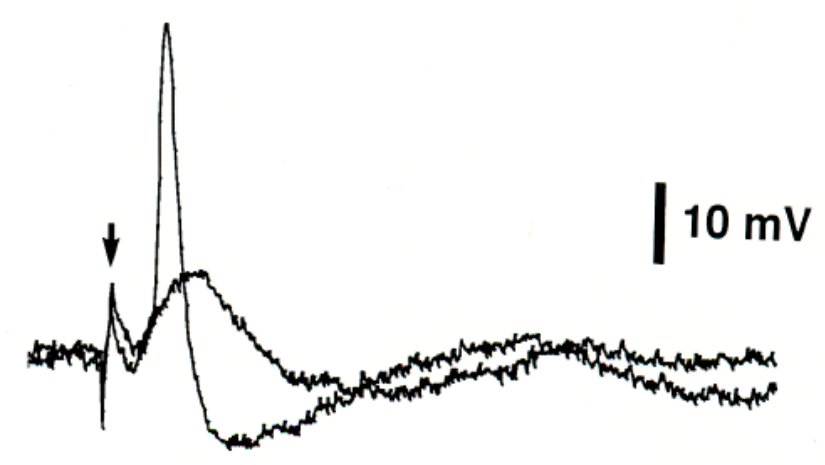

$20 \mathrm{msec}$
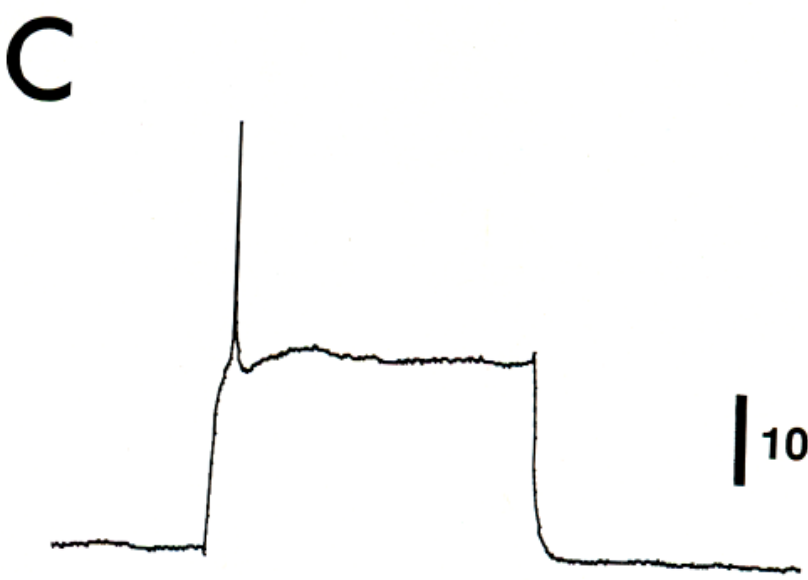

Figure 6. Morphology and physiology of a subplate neuron at P9. A, The cell body is located in the subplate near the border with the cortical plate. Cell body and dendrites, shown in black, display a bipolar morphology. Axonal branches (red) are found in both the subplate and the cortical plate; many end in growth cones. $B$, Electrical stimulation of the radiations (arrow) elicits EPSPs (low intensity) or synaptic spikes (higher intensity) followed by an afterhyperpolarization. $C$, This cell responded in a single spiking pattern to injection of depolarizing current.

neurons were located in the upper part of the subplate, very close to layer 6 of the cortical plate. One example is shown at P4 in Figure 9D. This cell has a pyramidal-shaped soma and a characteristic spray of basal dendrites. In many respects, it resembles a layer 6 pyramidal neuron, both in its dendritic branching pattern and in having an ascending axon collateral (Gilbert and Wiesel, 1979; Gilbert, 1983; Martin and Whitteridge, 1984; Katz, 1987). However, this neuron is most likely a subplate neuron, rather than a displaced layer 6 neuron, because previous ${ }^{3} \mathrm{H}$-thymidine labeling studies have shown that neurons generated at the end of the period of subplate neurogenesis come to reside at the base of the developing cortical plate, just beneath layer 6 . The majority of these neurons disappear by adulthood and are thus a part of the subplate (Luskin and Shatz, 1985a). Consistent with this interpretation, the axon collateral of this cell continues past layer 4 to terminate within the marginal zone (layer 1), whereas the axons of adult layer 6 neurons do not ascend beyond cortical layer 4 .

\section{Discussion}

The results of this intracellular recording study demonstrate that subplate neurons receive functional synaptic inputs during fetal and postnatal life. Moreover, they send a significant axonal projection into the overlying cortical plate, suggesting that they could participate both post- and presynaptically in a transient, but functional cortical microcircuit. The functional synaptic input to subplate neurons is present as early as E50 and persists into the perinatal period (P9), consistent with previous ultrastructural studies of fetal and neonatal subplate neurons indicating that they can receive synaptic contacts (Chun et al., 1987; Valverde and Facal-Valverde, 1988). The precise identity of the presynaptic inputs is as yet unknown, but a good possibility is 


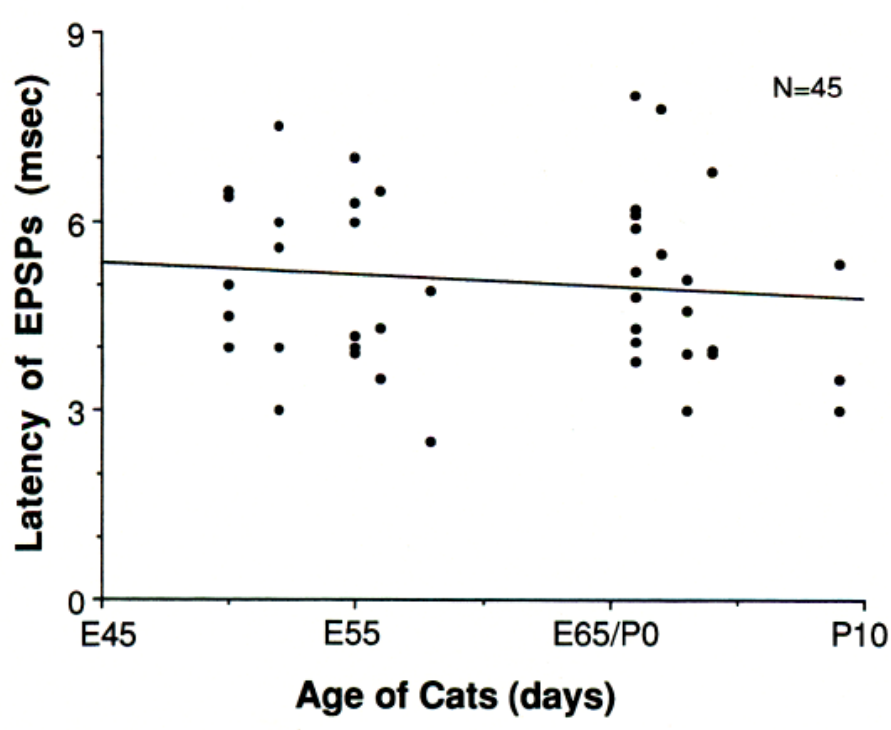

Figure 7. Latencies to the onset of the EPSPs plotted according to age. Forty-five cells were analyzed and a regression line drawn. There was no significant change with age.

that the waiting thalamocortical afferents supply at least some of the input. By E50, many thalamocortical axons have arrived within the subplate (Shatz and Luskin, 1986), where they branch extensively in the vicinity of subplate neurons (Ghosh et al., 1989). It is highly likely that our stimulating electrodes, located as they were in the optic radiations, activated many of these thalamocortical axons. Nevertheless, definitive proof awaits the direct electron microscopic demonstration that identified thalamic axons are presynaptic to subplate neurons.
There are several other possible sources of inputs to subplate neurons in addition to the thalamic axons. Other axonal systems, such as callosal axons (Wise and Jones, 1978; Innocenti, 1981), also wait in the subplate. Moreover, the descending axons of cortical neurons give off fine collateral side branches within the subplate (Cajal, 1911; S. K. McConnell, A. Ghosh, and C. J. Shatz, unpublished observations), and, as demonstrated here, the subplate neurons themselves make local axonal ramifications. In addition, subplate neurons send projections to the thalamus (McConnell et al., 1989). Thus, it is possible that electrical stimulation of the radiations activated subplate and cortical plate cells antidromically, which, in turn, elicited orthodromic EPSPs. However, since we observed routinely that the threshold for antidromic activation of subplate neurons was higher than that for orthodromically evoked EPSPs, we think it unlikely that the axon collaterals of subplate neurons contribute significantly to the observed EPSPs evoked at low thresholds.

Subplate neurons not only act as recipients of synaptic inputs, but also form extensive axon collaterals both within the subplate and within the cortical plate. Previous anatomical studies have also indicated the existence of projections from subplate to cortical plate neurons (Golgi: Valverde and Facal-Valverde, 1988; immunostaining with peptide antibodies: Wahle et al., 1987; Chun and Shatz, 1989a). However, the intracellular injection techniques used here underscore the extensive nature of these axonal connections, which previously have not been seen in such detail due to technical limitations inherent in the Golgi and immunostaining techniques. Although we cannot be entirely certain due to sampling problems (the youngest cells were difficult to impale and fill), our results suggest that there is a gradual increase in the complexity of the axonal arborization extended within the cortical plate. Early on, axons are smooth
Figure 8. Morphology of a subplate neuron injected at P1. Most of the axonal branches enter the cortical plate. Cell body and dendrites of this multipolar neuron are shown in black. Axon collaterals (red) are found both within the subplate and in the cortical plate. Note the many branches found in layers 1 and 4 and the broad tangential extent of the arborization.

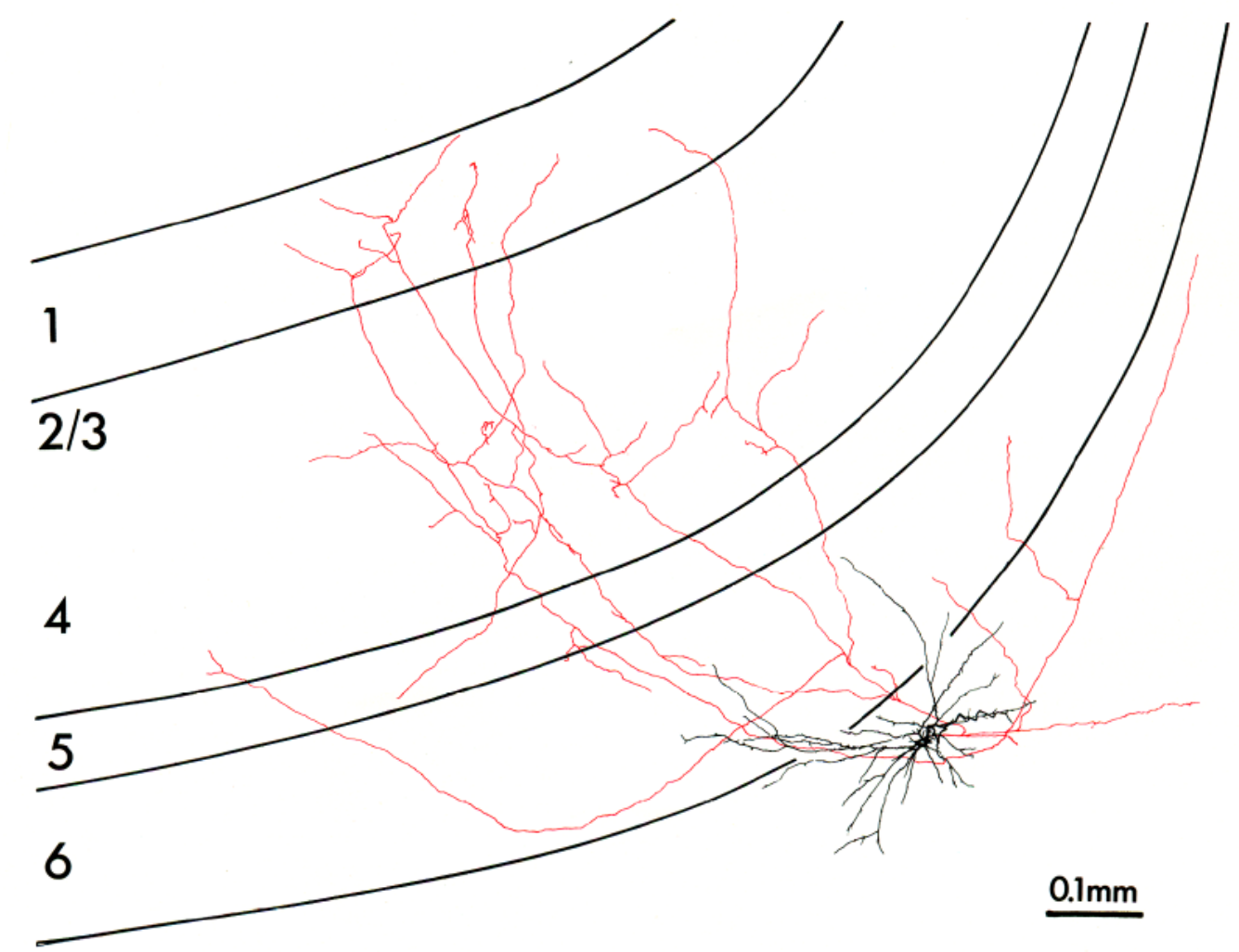




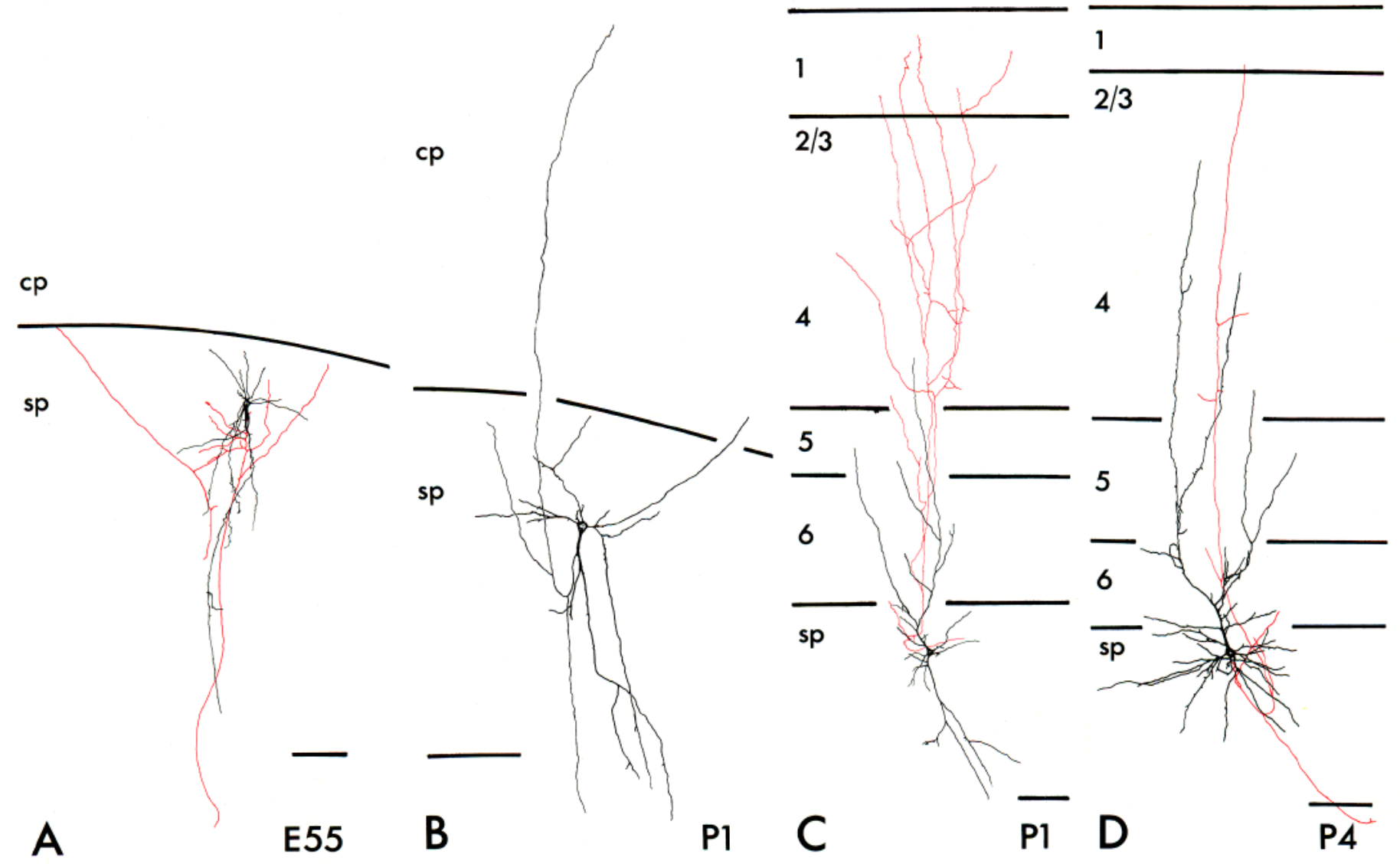

Figure 9. Biocytin-injected subplate neurons at E55 $(A), \mathrm{P} 1(B, C)$, and $\mathrm{P} 4(D) . A$ and $B$ are inverted pyramids, $C$ is a bipolar cell, and $D$ is a regular pyramidal neuron. Note the ascending axon collaterals that enter the cortical plate and branch within layer 4 at older ages. Axons in $A$, $C$, and $D$ are shown in red. Scale bar in each case is $0.1 \mathrm{~mm}$.

and may terminate in the marginal zone, whereas by birth, they can also have branches within layer 4 , the major recipient zone for thalamocortical axons (Garey and Powell, 1971; LeVay and Gilbert, 1976; Ferster and Lindström, 1983). Since subplate neurons are known to express immunoreactivity for neuropeptides and glutamic acid decarboxylase and GABA as early as E50, and to retrogradely transport ${ }^{3} \mathrm{H}$-aspartate (Antonini and Shatz, 1989; Chun and Shatz, 1989a, b), they are well equipped to synaptically influence cortical neurons. If so, the details of the circuitry would be expected to change with age and, of course, to disappear with the death of subplate neurons. As argued above, subplate neurons are likely to receive direct synaptic input from thalamocortical axons, and they send an axon into the cortical plate which terminates both in the marginal zone (layer 1) and in cortical layer 4. This observation raises the possibility that both marginal zone neurons and the neurons of layer 4 receive synaptic inputs from subplate neurons during development. Ongoing studies using current source density analysis in fetal cortical slices support this suggestion (Friauf et al., 1989; E. Friauf and C. J. Shatz, in preparation). Results of these studies indicate that stimulation of the optic radiations evokes short-latency, monosynaptic excitation confined to the subplate and long-latency, polysynaptic excitation within layer 4, which we believe could be mediated by the ascending axons of the subplate neurons. With ensuing postnatal life, the thalamocortical axons leave the subplate and innervate cortical layers 4 and 6 , and the subplate neurons die. Thus, subplate neurons may act as a transient synaptic link between the thalamic axons and the developing cortical layers.

It is perhaps surprising that subplate neurons with functional synaptic inputs remain at later ages (P9) because at least half of the subplate population has already been eliminated by cell death and the vast majority of waiting thalamocortical axons have already invaded cortical layer 4 . However, the fact that the neuron illustrated in Figure 6 sits in the upper part of the subplate-close to layer 6-and also possesses elaborate dendrites located within the cortical plate might permit it to receive synaptic input from the maturing thalamocortical axons that are known in the adult to send collaterals to layer 6 as well as layer 4 (Ferster and Lindström, 1983). Another possibility is that these subplate neurons are postsynaptic to other axons within the white matter, such as callosal axons, that are known also to wait in the subplate and to invade the cortical plate later during postnatal life (Wise and Jones, 1978; Innocenti, 1981). Finally, at least $10 \%$ of the subplate neurons survive the period of cell death and persist into adulthood (Chun and Shatz, 1989b), where they may in fact participate in persistent synaptic circuits in adult animals (Kostovic and Rakic, 1980).

\section{Physiological properties of subplate neurons}

In contrast to the suggested morphological changes in subplate neurons with age, we found very little evidence for substantial alterations in the physiological properties of subplate neurons. There is a modest decrease in EPSP latency that could be due 
to an increase in conduction velocity of the afferents or to an increase in the efficacy of synaptic transmission. Similar latency changes have been reported in studies of developing cortex (Kriegstein et al., 1987) and cochlear nucleus (Wu and Oertel, 1987).

With regard to the firing patterns of subplate neurons, we found evidence for the presence of at least one cell category that is similar to cortical neurons studied in vitro in the adult: the regular spiking cells of McCormick et al. (1985). However, we never saw bursters or fast spiking cells. The absence of bursters is consistent with the findings of Kriegstein et al. (1987), who also noted their absence in neonatal slices of rodent neocortex. On the other hand, we found 2 additional cell types: single spiking and adapting neurons. Furthermore, unlike in the adult when an EPSP can elicit a train of spikes in the postsynaptic cell, in subplate neurons EPSPs never elicited more than a single spike. Within the 3 categories of cells that we found, only single spiking neurons were observed before birth. However, we do not think that single spiking neurons represent immature cells that may turn into adapting or regular spiking cells during development since we could find single spiking subplate neurons even at P9 when subplate neurons have peaked in maturity. In this context it is striking that a recent physiological study of spinal cord dorsal horn neurons has found 3 spiking patterns very similar to those reported here (Thomson et al., 1989). Since this study was done in adult animals, the observed categories are not necessarily diagnostic of immature cells only.

A major question concerns the extent to which our sample size is representative of the entire population of subplate neurons. In this regard it is comforting to note that the morphological types described here include all of those described previously in Golgi and neuropeptide immunostaining studies. Hence, it is unlikely that a subpopulation of subplate neurons has been omitted. Nonetheless, our method may have selected for larger cells, a bias that is manifested in all intracellular recording techniques. We intentionally biased samples toward subplate neurons located in the relatively cell-dense upper half of the intermediate zone/white matter in order to improve the probability of impaling cells. There are also subplate neurons located closer to the ventricular zone (Chun and Shatz, 1989a) which we have not analyzed.

Previous studies on mature cortex have found striking correlations between the spiking patterns of neurons and their morphologies (Connors et al., 1982; McCormick et al., 1985). No such correlations were evident here. For instance, an inverted pyramidal cell at $\mathrm{P} 4$ responded to depolarizing current injection with only a single spike, whereas another inverted pyramid at P1 was a regular spiking neuron (see Table 1). Cells with bipolar morphologies could also have a single spiking pattern. It is possible that correlations do exist between the spiking pattern and other morphological properties such as neurotransmitter phenotype or projection patterns. These features were not characterized in our study.

\section{Functional significance of the circuit}

The results of this study indicate that subplate neurons receive monosynaptic input from axons in the developing white matter and may, in turn, relay their information to neurons of the cortical plate, mainly to layers 1 and 4 . Some subplate neurons are also known to send a descending axon to subcortical structures such as the thalamus, implying that synaptic input to subplate neurons could in theory drive both cortical and subcortical circuitries long before the neurons of the cortical plate are mature. We think it is likely that the circuit also works in vivo, for several reasons. Extracellular multiunit microelectrode recordings from the cortex of neonatal kittens indicate that spontaneously generated spikes can be recorded just below the cortical plate before similar activity can be seen within the cortical plate (Huttenlocher, 1967). We think it likely that these recordings were from subplate neurons. In the mammalian visual system, such spontaneous activity may be driven by thalamic input from LGN neurons, which in turn receive functional synaptic input from retinal ganglion cells (Shatz and Kirkwood, 1984), which are known to be spontaneously active in utero long before photoreceptors mature (Galli and Maffei, 1989; Meister et al., 1990). Thus, subplate neurons may be active in utero.

Since at least some of the synapses onto subplate neurons are active, the question arises as to the functional significance of the circuit. There are now many well-known examples in which neuronal activity is required for the normal patterning of connections in development (cf. Boss and Schmidt, 1984; Constantine-Paton and Reh, 1985; Stryker and Harris, 1986; Shatz and Stryker, 1988), and it is reasonable to propose that similar activity-dependent interactions occur in the subplate. Such interactions might subserve the process of topographic ordering of the thalamic projections in a manner similar to that known to occur during the development and regeneration of the retinotectal projection (for review, see Fawcett and O'Leary, 1985). In this way, thalamic axons could achieve some measure of topographic order prior to invading the cortical plate.

An alternative, though not mutually exclusive, possibility is that synaptically driven interactions within the subplate may mediate the process whereby ingrowing axonal systems select the appropriate cortical target area, i.e., auditory versus visual cortex. Results from recent ablation studies support this suggestion. When subplate neurons in fetal cats are destroyed by injections of kainic acid, geniculocortical axons that normally recognize and invade the visual cortex fail to do so. Rather, they are rerouted beyond their normal target cortical area into foreign regions of the telencephalon (Ghosh et al., 1989). These observations suggest that interactions between subplate neurons and waiting axons, possibly mediated by synaptic transmission, are crucial for the normal process of cortical target selection and ingrowth. If either of these 2 activity-dependent processes in fact occurs during cortical development, we would hypothesize that blockade of action potential activity using tetrodotoxin should disrupt topographic ordering or target selection by thalamocortical axons, similar to the situation already described in the retinogeniculate pathway (Sretavan et al., 1988).

Finally, the presence of subplate axon collaterals within the cortical plate raises the possibility that subplate neurons may also play a role in controlling the differentiation of cortical neurons. One way in which this might occur is if subplate neurons influence the excitability or endogenous calcium levels of cortical neurons, both of which have been implicated in the control of axonal and dendritic outgrowth in other systems (cf. Kater et al., 1988). Another possibility is that the peptides known to be present in subplate neurons might be released and act to influence the phenotypic differentiation of cortical neurons, as has been reported for the action of calcitonin gene-related peptide on the mitral cells of the olfactory bulb (Denis-Donini, 1989). While at present we cannot distinguish between these possibilities, the pivotal position of the subplate neurons in transient functional microcircuits suggests that the subplate neurons act as crucial links in coordinating the development of axons and their targets in the cortical plate. 


\section{References}

Antonini A, Shatz CJ (1990) Relationship between putative transmitter phenotypes and projection patterns of subplate neurons during cerebral cortical development. Eur J Neurosci (in press).

Boss VC, Schmidt JT (1984) Activity and the formation of ocular dominance patches in dually innervated tectum of goldfish. J Neurosci 4:2891-2905.

Choi DW, Koh J, Peters S (1988) Pharmacology of glutamate neurotoxicity in cortical cell culture: attenuation by NMDA antagonists. J. Neurosci 8:185-196.

Chun JJM, Shatz CJ (1988a) Redistribution of synaptic vesicle antigens is correlated with the disappearance of a transient synaptic zone in the developing cerebral cortex. Neuron 1:297-310.

Chun JJM, Shatz CJ (1988b) A fibronectin-like molecule is present in the developing cat cerebral cortex and is correlated with subplate neurons. J Cell Biol 106:857-872.

Chun JJM, Shatz CJ (1989a) The earliest-generated neurons of the cat cerebral cortex: characterization by MAP2 and neurotransmitter immunohistochemistry during fetal life. J Neurosci 9:1648-1667.

Chun JJM, Shatz CJ (1989b) Interstitial cells of the adult neocortical white matter are the remnant of the early generated subplate neuron population. J Comp Neurol 282:555-569.

Chun JJM, Nakamura MJ, Shatz CJ (1987) Transient cells of the developing mammalian telencephalon are peptide-immunoreactive neurons. Nature 325:617-620.

Connors BW, Gutnick MJ, Prince DA (1982) Electrophysiological properties of neocortical neurons in vitro. J Neurophysiol 48:302320.

Constantine-Paton M, Reh TA (1985) Dynamic synaptic interactions during the formation of a retinotopic map. In: Neurobiology: molecular biological approaches to understanding neuronal function and development (O'Lague P, ed), pp 151-168. New York: Liss.

Denis-Donini S (1989) Expression of dopaminergic phenotypes in the mouse olfactory bulb induced by the calcitonin gene-related peptide. Nature 339:701-703.

Fawcett JW, O'Leary DPM (1985) The role of electrical activity in the formation of topographic map in the nervous system. Trends in Neurosci 8:201-206.

Ferster D, Lindström S (1983) An intracellular analysis of geniculocortical and intracortical connectivity in area 17 of the cat. J Physiol (Lond) 342:181-216.

FriaufE, McConnell SK, Shatz CJ (1989) Subplate cells in visual cortex function in transient synaptic microcircuits. Soc Neurosci Abstr 15: 4.2 .

Galli L, Maffei L (1989) Spontaneous impulse activity of rat retinal ganglion cells in prenatal life. Science 242:90-91.

Garey LJ, Powell TPS (1971) An experimental study of the termination of the lateral geniculocortical pathway in the cat and monkey. Proc Roy Soc Lond Ser B 179:1-63.

Ghosh A, Antonini A, McConnell SK, Shatz CJ (1989) Ablation of subplate neurons alters the development of geniculocortical axons. Soc Neurosci Abstr 15:382.8.

Gilbert CD (1983) Microcircuitry of the visual cortex. Annu Rev Neurosci 6:217-248.

Gilbert CD, Wiesel TN (1979) Morphology and intracortical projections of functionally characterised ncurons in the cat visual cortex. Nature 280:120-125.

Horikawa K, Armstrong WE (1988) A versatile means of intracellular labeling: injection of biocytin and its detection with avidin conjugates. J Neurosci Meth 25:1-11.

Huttenlocher PR (1967) Development of cortical neuronal activity in the neonatal cat. Exp Neurol 17:247-262.

Innocenti GM (1981) Growth and reshaping of axons in the establishment of visual callosal connections. Science 212:824-827.

Kater SB, Mattson MP, Cohan C, Connor J (1988) Calcium regulation of the neuronal growth cone. Trends Neurosci 11:315-321.

Katz LC (1987) Local circuitry of identified projection neurons in cat visual cortex brain slices. J Neurosci 7:1223-1249.

Kostovic I, Molliver ME (1974) A new interpretation of the laminar development of cerebral cortex: synaptogenesis in different laycrs of neopallium in the human fetus. Anat Rec 178:395.

Kostovic I, Rakic P (1980) Cytology and time of origin of interstitial neurons in the white matter in infant and adult human and monkey telencephalon. J Neurocytol 9:219-242.
Kriegstein AR, Suppes T, Prince DA (1987) Cellular and synaptic physiology and epileptogenesis of developing rat neocortical neurons in vitro. Dev Brain Res 34:161-171.

LeVay S, Gilbert CD (1976) Laminar patterns of geniculocortical projection in the cat. Brain Res 113:1-19.

Luskin MB, Shatz CJ (1985a) Cogeneration of subplate and marginal zone cells in the cat's primary visual cortex. J Neurosci 5:1062-1075.

Luskin MB, Shatz CJ (1985b) Neurogenesis of the cat's primary visual cortex. J Comp Neurol 242:611-631.

Marin-Padilla M (1971) Early prenatal ontogenesis of the cerebral cortex (neocortex) of the cat (Felis domestica). A Golgi study. I. The primordial neocortical organization. Z Anat Entwick Gesch 134:117145.

Martin KAC, Whitteridge D (1984) Form, function and intracortical projections of spiny neurons in the striate cortex of the cat. J Physiol (Lond) 353:463-504.

McConnell SK, Ghosh A, Shatz CJ (1989) Subplate neurons pioneer the first axon pathway from the cerebral cortex. Science 245:978982.

McCormick DA, Prince DA (1987) Postnatal development of electrophysiological properties of rat cerebral cortical neurones. J Physiol 393:743-762.

McCormick DA, Connors BW, Lighthall JW, Prince DA (1985) Comparative electrophysiology of pyramidal and sparsely spiny stellate neurons of the neocortex. J Neurophysiol 54:782-806.

Meister M, Wong ROL, Baylor DA, Shatz CI (1990) Synchronous bursting activity in ganglion cells of the developing mammalian retina. Invest Ophthalmol Vis Sci 31:115.

Molliver ME, Kostovic I, Van der Loos H (1973) The development of synapses in cerebral cortex of the human fetus. Brain Res 50:403407.

Ramón y Cajal S (1911) Histologie du system nerveux de l'homme et des vertebres, vol II. Paris: Maloine (reprinted Madrid, 1952).

Shatz CJ, Kirkwood PA (1984) Prenatal development of functional connections in the cat's retinogeniculate pathway. J Neurosci 4:13781397.

Shatz CJ, Luskin MB (1986) The relationship between the geniculocortical afferents and their cortical target cells during development of the cat's primary visual cortex. J Neurosci 6:3655-3668.

Shat7 CJ, Stryker MP (1988) Formation of eye-specific layers in the lateral geniculate nucleus is blocked by tetrodotoxin. Science $242: 87-$ 89.

Stretavan DW, Shatz CJ, Stryker MP (1988) Modification of retinal ganglion cell axon morphology by prenatal infusion of tetrodotoxin. Nature 336:468-471.

Stryker MP, Harris WA (1986) Binocular impulse blockade prevents the formation of ocular dominance columns in cat visual cortex. J Neurosci 6:2117-2133.

Thomson AM, West DC, Headley PM (1989) Membrane characteristics and synaptic responsiveness of superficial dorsal horn neurons in a slice preparation of adult rat spinal cord. Eur J Neurosci 1:479488 .

Valverde F, Facal-Valverde MV (1987) Transitory population of cells in the temporal cortex of kittens. Dev Brain Res 32:283-288.

Valverde F, Facal-Valverde MV (1988) Postnatal development of interstitial (subplate) cells in the white matter of the temporal cortex of kittens: a correlated Golgi and electron microscopic study. J Comp Neurol 269:168-192.

Wahle P, Meyer G (1987) Morphology and postnatal changes of transient NPY-ir neuronal populations during early postnatal development of the cat visual cortex. J Comp Neurol 261:165-195.

Wahle P, Meyer G, Wu J-Y, Albus K (1987) Morphology and axon terminal pattern of glutamate decarboxylase-immunoreactive cell types in the white matter of the cat occipital cortex during early postnatal development. Dev Brain Res 36:53-61.

Watkins JC, Olverman HJ (1987) Agonists and antagonists for excitatory amino acid receptors. Trends Neurosci 10:265-272.

Wise SP, Jones EG (1978) Developmental studies of thalamocortical and commissural connections in the rat somatic sensory cortex. $\mathbf{J}$ Comp Neurol 175:187-208.

Wu SH, Oertel D (1987) Maturation of synapses and electrical properties of cells in the cochlear nuclei. Hearing Res 30:99-110. 